\title{
CENTRO DE PESQUISA E DOCUMENTAÇÃO DA HISTÓRIA POLÍTICA DO RIO GRANDE DO SUL
}

\author{
Carmen Silvia Aragones Aita \\ Mestre Fapergs/PUCRS e pesquisadora do CPDHPRS \\ Gunter Axt \\ Mestre Fapergs/UFRGS, doutorando - DH/FFLCH/USP e pesquisador CPDHPRS \\ Vladimir Araújo \\ Doutorando em Ciência da Comunicação e Informaçāo - Paris II - Coordenador do CPDHPRS
}

O Centro de Pesquisa e Documentação da História Política do Rio Grande do Sul (CPDHPRS) é um órgão vinculado à Diretoria de Atividades $\mathrm{Cul}$ turais (DAC) da Assembléia Legislativa do Estado do Rio Grande do Sul (ALRS). Encontra-se estruturado no prédio Solar dos Câmara, antiga residência dos Viscondes de São Leopoldo e de Pelotas, cuja construçāo, em estilo colonial, foi concluída em 1818. Prédio de inestimável valor histórico, pois trata-se do segundo mais antigo preservado na Cidade de Porto Alegre, foi tombado em 1963. Tendo sido adquirido pela Assembléia Legislativa do Rio Grande do Sul em 1981, foi inteiramente restaurado por este poder, concluindo-se as obras em 1993. O digno casarão possui mais de 20 peças, perfazendo ao todo cerca de $700 \mathrm{~m} 2$ de área construída, nas quais se distribuem a Biblioteca da Assembléia Legislativa, o Centro de Pesquisa e Documentação e o Serviço de Atividades Culturais da ALRS.
O Centro de Pesquisa e Documentação foi criado em 20/12/1967, pela Lei estadual $n^{\circ} 1587$, mas inaugurado efetivamente apenas em 19 de setembro de 1978, sob a designação de Serviço de Pesquisa, Documentação Histórica e Museu da Assembléia Legislativa. Fixando-se no Solar dos Câmara em 1993, assumiu a denominação de Centro de Pesquisa e Documentação da História Política do Rio Grande do Sul em 1996, a partir da implantação do "Projeto Memória do Parlamento".

Originalmente, o Centro foi constituído para abrigar o acervo mais antigo sob guarda da Assembléia do Rio Grande do Sul, composto basicamente de documentos avulsos dos séculos XVIII e XIX, Atas e Anais do Conselho Administrativo, do Conselho Geral da Província, da Assembléia Provincial e da Assembléia dos Representantes do R.S. Reúne, ainda, as coleçōes de Leis, Atos e Resoluçōes da Província do Rio Grande do Sul e do Im- 
pério. A hemeroteca do Centro conserva a coleção quase completa do jornal republicano oficial $\mathrm{A} \mathrm{Fe}$ deração (1884-1937), bem como alguns volumes do Jornal do Estado e coleções menores de periódicos do período farroupilha (1835-1845) ou alguns suplementos isolados da década de 1870. Embora a ênfase do acervo privilegie o Estado do Rio Grande do Sul, o Centro também dispōe das coleçōes quase completas dos Anais do Senado e da Câmara dos Deputados, desde sua fundação, sob o Império, até a Constituinte de 1946, além de partes das coleçōes dos Anais da Assembléia do Estado de São Paulo (1875-1935) e de volumes esparsos das Assembléias dos Estados do Rio de Janeiro, Pernambuco, Espírito Santo e Minas Gerais. Por outro lado, a despeito da maior parte do acervo corresponder a fontes produzidas pelos Poderes Legislativos, o Centro abriga igualmente as mensagens do Presidente da Província, do Presidentc do Estado do RS e da Interventoria (da década de 1930 e sob o Estado Novo) à Assembléia Legislativa, bem como parte das Falas do Trono.

Também acham-se guardados junto ao acervo diversos relatórios das várias Secretarias de Estado do RS e de repartições administrativas do Poder Executivo, especialmente relativos à assim chamada República Velha. O Poder Judiciário, por scu turno, acha-se representado com as coleçõcs das Decisões do Superior Tribunal do RS, relativas ao período de 1895 a 1933. Finalmente, o Centro herdou alguns volumes da antiga biblioteca da família Câmara, com destaque para a bibliografia de caráter militar, religioso, sociológico c literário, dentre os quais encontram-se algumas obras raras, como ediçōes originais de Saint Hilaire autografadas ao Visconde de São Leopoldo, ediçōes da obra de Júlio Verne de 1877 e algumas ediçōes de sociólogos positivistas franceses dos anos 10,20 e 30 do século XX. Encontra-se também sob cuidados do CPDHPRS um rico exemplar da Constituição Esta- dual de 1891, ornado em ouro. Também do período da Primeira República sāo alguns catálogos comemorativos ou propagandísticos sobre o RS, feitos publicar pelo governo Borges de Medeiros ou pelo Partido Republicano Rio Grandense, que constituem importante fonte para o estudo da formação eco. nômica e social da época.

Embora dirigido à preservação da memória parlamentar gaúcha, com o tempo o CPDHPRS passou a absorver uma documentação mais recente $e$ diversificada, oriunda dos arquivos pessoais de de. putados, do Tribunal Superior Eleitoral, dos partidos políticos contemporâneos etc., fazendo crescer especialmente o acervo de documentação avulsa. Completam este patrimônio cerca de 120 depoimentos coletados sobretudo junto a políticos sul-riograndenses e aproximadamentc 100 rolos de fitas que guardam as sessões da última Assembléia Constituinte gaúcha. O CPDHPRS também dispōe de um arquivo fotográfico com cerca de 3.000 fotos, que remontam ao século XIX, com ênfase em personagens c fatos políticos do estado, bem como no espaço urbano que compõe as imcdiações do Solar dos Câmara e do Palácio Farroupilha, em Porto Alegre. Recentemente, foram ainda adquiridas junto à Fundação Getúlio Vargas alguns arquivos microfilmados, como o de Getúlio Vargas, Oswaldo Aranha e Lindolfo Collor, os quais estão à disposição dos constituintes nas leitoras copiadoras do Centro.

$O$ acervo do CPDHPRS acha-se relativamente bem cstrulurado segundo as normas de arquivística moderna, no que dizem respeito à acomodação e à catalogação. Com a implantação do "Projeto Memória do Parlamento" em inícios de 1996, este trabaIho tomou um novo alento. O acervo do Centro tem, assim, passado por um amplo processo de documentos danificados, o que tem implicado em um alto investimento em conservação e preservaçāo, inteiramente suportados pela ALRS. As atividades de restauração têm alcançado sobretudo a preciosa co- 


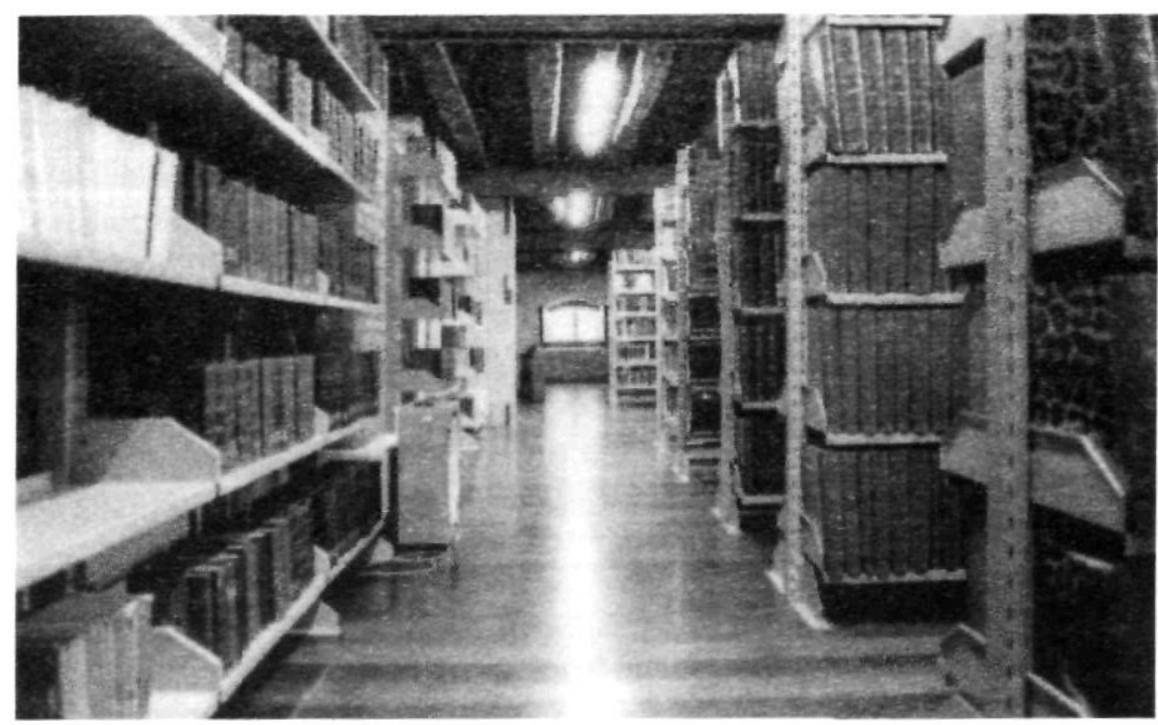

Centro de Pesquisa e Documentação da História

leção da hemeroteca, especialmente A Federação, as Atas e Anais mais antigos, particularmente os volumes manuscritos, e, finalmente, as obras raras. Dado a dimensão relativamente pequena do acervo do Centro - cerca de 4.000 volumes e 15.000 documentos avulsos -, o trabalho de restauro e reencadernação tem sido contratado a firmas particulares, não dispondo, portanto, o Centro de laboratórios próprios. Está prevista ainda a informatização gradual da catalogação e das fontes primárias, além da publicação dos catálogos relativos à documentação geral sob guarda do CPDHPRS, devendo os primeiros exemplares serem lançados ainda durante o ano de 1996. A coleção dos Anais da ALRTS, em especial, está ingressando em processo de microfilmagem. Concluída esta etapa, o Centro incentivará a retomada do Programa de História Oral e o aumento de acervo documental, sobretudo com a coleta de arquivos privados/familiares e com a reunião da documentação institucional-legislativa contemporânea.
O Projeto Memória do Parlamento propiciou ainda o desencadeamento de atividades de pesquisa histórica promovidas pelo CPDHPRS. A ênfase tem recaído sobre o resgate da trajetória institucional da ALRS, a partir da publicação de caracterizações históricas e de compilações de discursos significativos, especialmente representativos do período imperial. Também estão sendo elaborados perfis de parlamentares gaúchos, com base sobretudo na documentação em poder do Centro, os quais darão igualmente origem a publicações - sendo a primeira prevista sobre João Neves da Fontoura. Além disso, as pesquisas do Projeto Memória do Parlamento têm se orientado no sentido da formação de um banco de Dados da Atividade Parlamentar Sul-Riograndense, para o qual o passo inicial foi a confecção de um minucioso catálogo que reúne numa só edição todos os representantes gaúchos, titulares e suplentes, junto às três instâncias do Poder Legislativo - Assembléia, Câmara dos Deputados e Senado - de 1821 a 1996. 
Embora o CPDHPRS reúna um acervo de dimensōes menos assinaláveis, em relaçăo a outros arquivos da capital gaúcha e do centro do país, a sua importância reside na significativa expressão da documentação aos seus cuidados para tecitura da historiografia regional; em parte porque uma boa parcela de seu acervo não pode ser encontrada em outras instituiçōes, em parte porque permite aos consulentes o acesso, no Rio Grande do Sul, a fontes guardadas apenas em arquivos do centro do país, e, ainda em virtude dos investimentos em restauração e conservação que contribuem para preservar fontes que em outros arquivos gaúchos estāo ameaçadas pela degeneração material. Finalmente, a promoção de ati. vidades de pesquisa pelo CPDHPRS traz a lume os primórdios da atividade parlamentar no Rio Grande do Sul, contribuindo para o resgate da memória política regional. 